Quebec Cooperative Study

of Friedreich's Ataxia

\title{
Amino Acid Changes in the Mouse Mutant Dystonia Musculorum Similar to Those in Friedreich's Ataxia
}

\author{
A. MESSER
}

SUMMARY: An autosomal recessive mutant strain of mouse with a progressive neurological disorder is described. Histopathology is dramatic in the sensory afferents and in the red nucleus. In the cerebellar vermis the concentrations of glutamate, aspartate, glycine and GABA are significantly reduced, and in the cerebellar hemispheres the taurine/glutamate ratio is elevated. These mice may provide a useful experimental model of Friedreich's ataxia.

RÉSUMÉ: Nous décrivons une souche de souris à hérédité autosomale récessive qui présente un désordre neurologique progressif. L'histopathologie est dramatique au niveau des afférences sensorielles et du noyau rouge. Dans le vermis cérébelleux les concentrations de glutamate, d'aspartate, de glycine et de $G A B A$ sont considérablement diminuées alors que le rapport taurine/glutamate est élevé au niveau des hémisphères cérébelleuses. Ces souris présentent peut-être un modele utile à l'étude de l'ataxie de Friedreich.

From the Birth Defects Institute, Center for Laboratories and Research, New York State Department of Health, Albany, New York.

Reprint requests for the entire supplement on Friedreich's Ataxia (Phase Three, Part Two) to: Prof. André Barbeau, Clinical Research Institute of Montreal, 110 West Pine Avenue, Montreal, Quebec, Canada, H2W $1 R 7$.

\section{INTRODUCTION}

The mouse mutant dystonia musculorum (dt) was first described by Duchen et al, (1964); a mutant autosomal recessive gene had occurred spontaneously in a randombred strain. Animals homozygous for this recessive gene begin to show incoordination and mild posturing during the second week of life. There is a rapidly progressive course leading to severe ataxia; nearly useless hind limbs (held stiffly out behind the mouse or shaking during twisting motions); forelimbs which are adducted-intorted, with digits spread and extended; and overall writhing motions with spasms and posturing, particularly of the hind limbs and tail (Duchen et al, 1964). An allelism test showed that this strain was allelic with the mutant "athetoid" $\left(d t^{\mathrm{J}}\right)$ at the Jackson Laboratory. Alleles seem to have arisen spontaneously in a large number of strains over the course of years (Sidman et al, 1965; E. Eicher, personal communication).

Pathology was seen mainly in the sensory pathways from the spinal cord cephalad to the thalamus. Massive axonal swelling and degeneration at both the light- (Duchen et al, 1964) and electron-microscopic (Janota, 1972) levels were sometimes recognizable as early as postnatal day 5 (i.e., before the onset of clinical signs). The pattern led Duchen to classify the syndrome as a "severe sensory ataxia," although he did note that not all of the symptoms could clearly be attributed to the observed sensory pathology. Histochemical studies of selected lysosomal hydrolases on animals 5-28 days old suggested an early defect of axonal transport in primary sensory neurons (Thornburg and Hanker, 1975; Hanker and Peach, 1976).
An allele of this mutant, $d t^{\mathrm{Alb}}$, has appeared spontaneously in a stock of $\mathrm{BALB} / \mathrm{cBy}$ mice maintained in the colony of Dr. Lorraine Flaherty at this Center. It produces the same timecourse for onset of symptoms as the alleles described above, but with special care the animals can be kept alive for several months. Dramatic pathological changes can be seen in the sensory afferents, particularly degeneration of large neurons in the dorsal root ganglion (Fig. 1), as well as in the large, coarse neurons of the caudal red nucleus (Messer and Strominger, 1980).

Reported neurochemical changes include a reduced capacity for wholecell biosynthesis of $\gamma$-aminobutyric acid (GABA) in the striatum and substantia nigra but not in the hypothalamus (Messer and Gordon, 1979) and increased turnover of norepinephrine in the cerebellum (Riker et al, 1981).

Many of the clinical signs and pathological changes in these mutants resemble Friedreich's ataxia more than dystonia. Here I report altered amino acid concentrations in $d t^{\mathrm{Alb}}$ mouse brains, which are similar to those reported in the brains of patients with Friedreich's ataxia (Huxtable et al, 1979).

\section{METHODS}

Histological methods are described in Messer et al, (1980).

Amino acid analyses were performed on the brains of three $d t^{\mathrm{Alb}}$ $/ d t^{\mathrm{Alb}}$ mice (two aged 6 weeks, one 16 weeks) and three age-matched $\mathrm{BALB} / \mathrm{cByJ}$ controls.

Anaesthetized mice were perfused with cold saline, the cerebellar hemispheres were separated from the vermis, and the cerebral cortex was peeled off a very thick coronal section. 
Tissue was homogenized in 20 volumes of $10 \%$ trichloroacetic acid, with norleucine added to measure recovery. After centrifugation the pellets were resuspended in $0.5 \mathrm{ml}$ of $1 \mathrm{~N} \mathrm{NaOH}$ for protein determination (Lowry et al, 1951). Supernatant amino acids were analyzed on a Beckman Model $121 \mathrm{M}$ amino acid analyzer equipped with AA-10 resin and a Nanobore flow system (by Dr. Bernyce Perelli, Peptide Core Facility, Laboratory of Human Reproduction and Reproductive Biology, Harvard Medical School).

Statistical analyses are by the Student's 2-tailed $t$ test.

\section{RESULTS}

Histopathologically, severe degeneration was seen in the large cells of the dorsal root ganglion (Fig. 1). As previously observed (Messer and Strominger, 1980), they showed eccentric nuclei, disrupted Nissl substance and central chromatolysis.

The amino acid analyses, done on three $d t^{A l b}$ mutants and three agematched BALB/C ByJ controls showed many suggestive trends and several statistically significant differences between $d t^{\prime} \mathrm{Alb}$ and control mice, even with this small sample (Table 1). In the cerebellar vermis glutamate, aspartate, glycine and GABA concentrations were all reduced, while in the cerebral cortex taurine, glutamate, GABA and tyrosine were all increased. Ratios of wet weight to protein, measured to assess changes in brain composition (e.g., dehydration) did not differ significantly between mutants and controls (Table 2).

Ratios of neurotransmitters to precursors within individual brains may give additional information (Huxtable et al, 1979). The only statistically significant change in cerebellar tissue was an increase in taurine/glutamate in the cerebellar hemispheres (Table 3). However, there also seemed to be increases in that ratio in the vermis, as well as taurine/GABA increases in both regions, which may reach significance with larger sample numbers (Table 3). Cortex also showed elevated taurine/glutamate and taurine/GABA (the former statistically significant), as well as a significant increase in glutamate/glutamine.

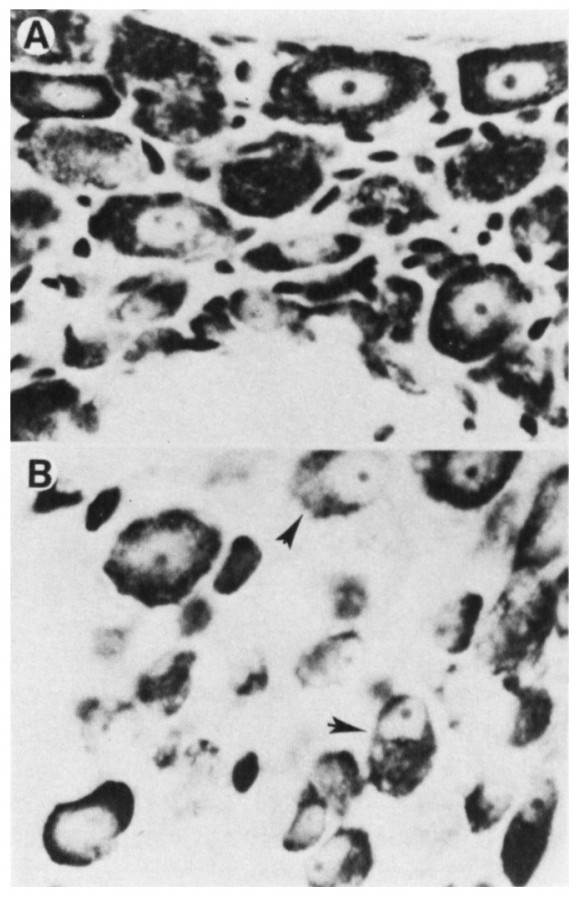

Figure 1 - Thionin-stained sections of dorsal root ganglion from (A) control mouse, and (B) $d t^{\mathrm{Alb}} / d t$ Alb mouse at 8 weeks. Note the reduced cell density and the severely disrupted cytoarchitecture of many remaining cells (arrows) in the mutant ( $x$ 1000).

TABLE 1

Amino Ac1d Content ( $\mu$ mole/g Wet Weight $+\mathrm{SEM} ; n=3$ )

VERMIS $^{a}$

Control

$4.08 \pm 0.022$

$10.02 \pm 0.37$

$3.18 \pm 0.15$

$2.33 \pm 0.02$

G1y

G1n

H1s

Tyr

Phe
$1.04 \pm 0.01$

$2.63 \pm 0.40$

$0.16 \pm 0.005$

$0.08 \pm 0.01$

$0.07 \pm 0.009$
$3.69 \pm 0.16$

$7.46 \pm 0.36 \star \star$

$2.45 \pm 0.2 *$

$1.58 \pm 0.17 *$

$0.87 \pm 0.05 *$

$2.34 \pm 0.36$

$0.19 \pm 0.01$

$0.079 \pm 0.005$

$0.061 \pm 0.003$

HEMIS

CORTEX

Control dt

$$
\begin{array}{r}
4.33 \pm 0.08 \\
10.46 \pm 0.44 \\
3.21 \pm 0.24 \\
2.16 \pm 0.12 \\
1.07 \pm 0.05 \\
2.65 \pm 0.31 \\
0.17 \pm 0.003 \\
0.08 \pm 0.006 \\
0.07 \pm 0.005
\end{array}
$$

$5.38 \pm 0.62$

$9.78 \pm 1.16$

$3.18 \pm 0.37$

$2.19 \pm 0.37$

$1.05 \pm 0.05$

$2.69 \pm 0.84$

$0.19 \pm 0.03$

$0.09 \pm 0.008$

$0.09 \pm 0.015$

$5.49 \pm 0.17$
$10.56 \pm 0.40$
$3.45 \pm 0.23$
$2.58 \pm 0.09$
$0.97 \pm 0.03$
$2.21 \pm 0.11$
$0.24 \pm 0.07$
$0.07 \pm 0.007$
$0.06 \pm 0.008$

$10.46 \pm 1.43 *$

$12.73 \pm 0.31 *$

$3.71 \pm 0.350$

$3.52 \pm 0.12 \star \star$

$1.04 \pm 0.06$

$1.51 \pm 0.24$

$0.18 \pm 0$

$0.11 \pm 0.004$ *

$0.08 \pm 0.003$

${ }^{*} \mathrm{p}<.05 ; * \star \mathrm{p}<.01$

a VERMIS, cerebellar vermis; HEMIS, cerebellar hemisphere; and CORTEX, cerebral cortex 
TABLE 2

Wet Weight/Protein Weight $( \pm \text { SEM; } n=3)^{a}$

VERMISB HEMIS CORTEX

\begin{tabular}{lccc}
\hline Control & $10.3 \pm 0.03$ & $10.1 \pm 0.2$ & $8.0 \pm 0.5$ \\
$\mathrm{dt} / \mathrm{dt}$ & $10.23 \pm 0.51$ & $9.55 \pm 0.04$ & $8.03 \pm 0.44$
\end{tabular}

a No significant differences

b VERMIS, cerebellar vermis; HEMIS, cerebellar hemisphere; and CORTEX, cerebral cortex

\section{DISCUSSION}

This autosomal recessive mouse mutant shows ataxia and tremor, as well as dystonic posturing. Some of these symptoms may be animal equivalents of those seen in Friedreich's ataxia; even the dystonic postures are not unknown in very advanced cases (A. Barbeau, personal communication). The fact that the disorder in mice is both hereditary and progressive offers many opportunities for developmental investigations.

Pathology in sensory afferents and especially in the large cells of the dorsal root ganglia has been reported in Friedreich's ataxia (Hughes et al, 1968; Peyronnard et al, 1967; LaMarche, this volume) and can clearly be seen in the mouse. Some instances of red nucleus changes have been shown at autopsy of patients with Friedreich's ataxia (Oppenheimer, 1979). If there are any pathological changes in the major cell types of the cerebellar cortex, they are not obvious and will be found only by careful quantitation of the human or mouse material.

Changes in the concentrations of cerebellar amino acid neurotransmitters have been reported after 3acetylpyridine treatment of rats, leading to neurological symptoms with no pathology in the cerebellar cortex (Nadi et al, 1977; Butterworth et al,
TABLE 3

Selected Amino Acid Ratios (+SEM; $n=3$ )

\begin{tabular}{lll}
\hline VERMIS $^{\mathrm{a}}$ & HEMIS & CORTEX \\
\hline
\end{tabular}

Control

$\begin{array}{llll}\text { Tau/Glu } & 0.41 \pm 0.003 & 0.42 \pm 0.02 & 0.520 \pm 0.013 \\ \text { Tau/GABA } & 1.75 \pm 0.08 & 1.82 \pm 0.25 & 2.14 \pm 0.12 \\ \text { GABA/G1u } & 0.21 \pm 0.004 & 0.21 \pm 0.003 & 0.25 \pm 0.02 \\ \text { Glu/Gln } & 4.07 \pm 0.84 & 3.01 \pm 1.10 & 4.82 \pm 0.41\end{array}$

$\underline{d t} / d t$

$\begin{array}{llll}\text { Tau/G1u } & 0.51 \pm 0.06 & 0.55 \pm 0.02 * & 0.817 \pm 0.10 * \\ \text { Tau/GABA } & 2.40 \pm 0.33 & 2.51 \pm 0.17 & 2.99 \pm 0.49 \\ \text { GABA/G1u } & 0.21 \pm 0.005 & 0.22 \pm 0.02 & 0.28 \pm 0.02 \\ \text { Glu/G1n } & 3.29 \pm 0.45 & 4.34 \pm 1.33 & 8.89 \pm 1.4 *\end{array}$

$\star_{p}<.05$

a VERMIS, cerebellar vermis; HEMIS, cerebellar hemisphere; and CORTEX, cerebral cortex 
1978), and in the mouse mutants staggerer and weaver, which lose granule cells and show glutamate reductions in both the grossly depleted cerebellar cortex and the relatively normal deep nuclei (Roffler-Tarlov and Sidman, 1978). Thus amino acid changes in animals do not seem to require concomitant histopathology.

Huxtable et al, (1979), studying brains of patients with Friedreich's ataxia, reported significant reductions in glutamate, GABA and phenylalanine, as well as suggestive reductions in aspartate and glycine, in parts of the cerebellum but not in the inferior olive, dentate, or red nucleus. These observations closely match the changes seen in the cerebellar vermis of $d t^{\mathrm{Alb}}$ mice, including statistically significant reductions in glutamate, aspartate, glycine and GABA. It is not clear why the hemisphere does not show equivalent changes. Differing ratios of cortical to deep nuclear tissue could be partially responsible.

Amino acid and GABA ratios also show some similarities to those of the human brains. In one ratio the hemisphere does show a statistically significant change. The differences are not due to non-specific factors such as dehydration, since the ratios of wet weight to protein do not differ between $d t_{\mathrm{Alb}}$ and controls.

The studies reported here suggest that the neurological mutant $d t^{\mathrm{A}}$ Ib should be further examined for its relationship to Friedreich's ataxia and that the role of the cortex should be considered in both the human and the mouse diseases.

\section{ACKNOWLEDGEMENTS}

Paul Maskin and Gary Snodgrass contributed expert technical assistance. Amino acid analyses were run by Dr. Bernyce Perelli, Laboratory of Human Reproduction and Reproductive Biology, Harvard Medical School. I thank Drs. Suzanne Tarlov and Norman Strominger for helpful discussions. The initial parts of this work were supported by a grant from the Dystonia Medical Research Foundation.

\section{REFERENCES}

BUTTERWORTH, R.F., HAMEL, E., LANDERVILLE, F. and BARBEAU, A. (1978). Cerebellar ataxia produced by 3acetyl pyridine in rat. Can. J. Neurol. Sci., 5, 131-133.

BUTTERWORTH, R.F., HAMEL, E., LANDERVILLE, F. and BARBEAU, A. (1979). Amino acid changes in thiamine deficient encephalopathy: some implications for the pathogenesis of Friedreich's ataxia. Can. J. Neurol. Sci., 6, 217-222.

DUCHEN, L.W., STRICH, S.T. and FALCONER, D.S. (1964). Clinical and pathological studies of an hereditary neuropathy in mice (dystonia musculorum). Brain, 87, 367-378.

HANKER, J.S. and PEACH, R. Histochemical and ultrastructural studies of primary sensory neurones in mice with dystonia musculorum. Neuropath. Appl. Neurobiol., 2, 79-97.

HUGHES, T.J., BROWNELL, B. and HEWER, R.L. (1968). The peripheral sensory pathway in Friedreich's ataxia. An examination by light and electron microscopy of the posterior nerve roots, sensory nerves in cases of Friedreich's ataxia. Brain, 91, 803-818.

HUXTABLE, R.J., AZARI, J., REISINE, T. JOHNSON, P., YAMAMURA, H.I. and BARBEAU, A. (1979). Regional distribution of amino acids in Friedreich's ataxia brains. Can. J. Neurol. Sci., 6, 255 258.

JANOTA, I. (1972). Ultrastructural studies of an hereditary sensory neuropathy in mice. (dystonia musculorum). Brain, 95, 529-536.
LOWRY, O.H., ROSEBROUGH, N.J., FARR, A.L. and RANDALL, R.J. (1951). Protein measurement with the folin phenol reagent. J. Biol. Chem., 193, 265-275.

MESSER, A., and GORDON, D. (1979). Changes in whole tissue biosynthesis of $\gamma$ aminobutyric acid (GABA) in basal ganglia of the dystonia (dtAlb) mouse. Life Sci., 25, 2217-2221.

MESSER, A. and STROMINGER, N.L. (1980). An allele of the mouse mutant $d y s$ tonia musculorum exhibits lesions in red nucleus and striatum. Neuroscience, 5, 543549.

NADI, N.S., KANTER, D., McBRIDE, W.J. and APRISON, M.H. (1977). Effects of 3 acetylpyridine on several putative neurotransmitter amino acids in the cerebellum and medulla of the rat. J. Neurochem., 28, 661-662.

OPPENHEIMER, D.R. (1979). Brain lesions in Friedreich's ataxia, Can. J. Neurol. Sci., 6, 173-176.

PEYRONNARD, J.M., LAPOINTE, L., BOUCHARD, J.P., LAMONTAGNE, A., LEMIEUX, B., and BARBEAU, A. (1976). Nerve conduction studies and electromyography in Friedreich's ataxia. Can. J. Neurol. Sci., 3, 313-317.

RIKER, D.K., MESSER, A., and ROTH, R.H. (1981). Increased noradrenergic metabolism in the cerebellum of the mouse mutant dystonia musculorum. J. Neurochem., 37, 649-654.

ROFFLER-TARLOV, S., and SIDMAN, R.L. (1978). Concentrations of glutamic acid in cerebellar cortex and deep nuclei of normal mice and weaver, staggerer and nervous mutants. Brain Res., 142, 269-283.

SIDMAN, R.L., GREEN, M.S., and APPEL, S.H. (1965). Catalog of the Neurological Mutants of the Mouse, Harvard University Press, Cambridge, Mass. pp. 19-21.

THORNBURG, L.P., and HANKER, J.S. (1975). Lysosomal hydrolases in the trigeminal ganglion of mice afflicted with an hereditary sensory neuropathy (dystonia mus. culorum). Acta Neuropat., (Berl) 32, 91. 101. 